\title{
Evaluating strategies to manage and endure challenging behaviors in mucopolysaccharidoses
}

\author{
Nathan Grant ${ }^{1 *}$ (1)
}

\begin{abstract}
The mucopolysaccharidoses (MPS) are a group of rare, genetic, lysosomal storage disorders characterized by progressive, multisystemic accumulation of glycosaminoglycans. Individuals with severe MPS often present with significant neurological involvement and may exhibit challenging behaviors, including hyperactivity, aggression, and sleep disturbance. These behaviors can cause adverse outcomes and necessitate the development of specific measures to support affected families. Through an analysis of the results reported by Hoffmann et al. in their recent study, this letter outlines important factors that must be considered when evaluating the impact of challenging behaviors associated with MPS, including treatment history, age, sibling and family relationships, the feasibility of daily caregiving, and caregiver burden. These recommendations can help guide future studies to identify the most effective coping strategies to support families of people with MPS who have challenging behaviors.
\end{abstract}

Keywords: Mucopolysaccharidoses, MPS, Challenging behavior, Aggression, Caregivers, Siblings, Coping, Support

For many years, my family has struggled to provide care for my twin brother because of his challenging behaviors. My brother has the neuronopathic form of mucopolysaccharidosis (MPS) type II, also known as severe Hunter syndrome. Like many people with this condition, my brother is nonverbal, has a significant intellectual disability, and requires continual care and assistance from multiple caregivers $[1,2]$. Although my parents and I assist my brother with daily living activities, including dressing, feeding, bathing, and toileting, it can be extremely difficult to provide care when my brother is agitated and aggressive. In the midst of changing my brother's diaper or dressing him, we have to carefully watch my brother's hands to ensure he does not punch us or pull our hair. Our attempts at self-defense are usually futile, however, leaving us with bruises running up our arms, scratches around our necks, torn clothes, and hair left scattered on

*Correspondence: nrgrant02@gmail.com

${ }^{1}$ Health, Medicine, and Society, University of Cambridge, Cambridge, UK the ground. Since my brother is nonverbal, it is difficult to ascertain the specific causes of his aggression and we have not found any strategies to effectively manage his challenging behaviors. My family lives in constant fear of my brother's next aggressive outburst, uncertain whether he approaches us to hug us or to harm us. The recent study by Hoffmann et al. [3] provides important and timely insights on practical coping strategies to manage challenging behaviors in MPS. However, some additional questions and implications must be addressed in order to provide the most effective support for people with MPS and their caregivers.

Hoffmann et al. surveyed families of children diagnosed with MPS I, II, and III with serious neurological involvement. While the researchers collected some sociodemographic information about the children with MPS, such as their age and gender, they did not fully assess the children's treatment history. Although Hoffmann et al. did report that one child had a history of MPS-specific therapy [3], it is unclear whether this therapy included 
enzyme replacement therapy (ERT), hematopoietic stem cell transplantation (HSCT), or another form of medical treatment. Furthermore, we are not provided information about the medical history of the other 33 children in the study. Medical treatment of any kind, including ERT, HSCT, anticonvulsants, pain management, treatment for spasticity, and surgeries, can significantly alter the behavioral manifestations of MPS [4]. For example, because many individuals with neuronopathic MPS have significant language impairment, they often exhibit challenging behaviors to communicate underlying medical issues, such as pain $[4,5]$. Accordingly, an individual who has received more treatment for pain may exhibit fewer challenging behaviors than someone who has not been adequately treated for pain, which can significantly affect the frequency of behavioral symptoms as well as the efficacy of the coping strategies reported in this study. It would be truly devastating for a family to continually employ strategies to distract or calm an aggressive child when the behavioral antecedents are actually somatic in nature and could be effectively addressed with some form of medical intervention. Therefore, future studies must consider the medical history of people with MPS to thoroughly examine the cause of behavior problems and identify effective strategies for support.

While Hoffmann et al. provide important information about challenging behaviors in children under the age of 18 , it is unfortunate that they did not include older participants in their study. Although the authors do not explicitly mention the reasons for this age limit, it is important to acknowledge that challenging behaviors still occur in people with MPS who are above the age of 18 [6]. The fact that two adults were excluded from the researchers' analysis [3] indicates that there is both interest and a need to study challenging behaviors in older populations. In fact, it can be even more difficult to manage behavior problems in adults with MPS because of their physical size and strength $[4,7,8]$. Often multiple caregivers are needed, including parents, siblings, as well as home health aides and direct support professionals [2, 4]. However, the national shortage of caregivers and dismally low financial compensation for caregiving makes it difficult for families to provide care for adults with severe behavior problems [9]. With limited resources for support, many families must consider residential facilities when they are no longer able to provide care at home [4, 6]. Accordingly, future studies must investigate the experiences of families who provide care for adults with MPS in order to develop appropriate resources for support.

In addition to researching the experiences of adults with MPS, we must also pay attention to other members in the family. Hoffmann et al. report that MPS can have a slightly negative impact on relationships with healthy siblings [3]. However, of the 20 participants who responded to the question about sibling relationships, the majority of responses were from parents and only one questionnaire was actually completed by a sibling. Siblings may provide care for their brothers and sisters with MPS throughout life, and the role of primary caregiver often transitions to siblings as parents age [7]. Given the limited support available for siblings $[7,10]$, challenging behaviors may cause siblings to experience more emotional stress than parents and may necessitate unique coping strategies specifically for siblings. Accordingly, more research is needed to directly investigate the perceptions of siblings themselves. Researchers must work closely with patient and family organizations to invite siblings to participate in future studies.

Some of the coping strategies identified by Hoffmann et al. also raise concerns about practicality. Several measures reported against challenging behaviors require the direct involvement of caregivers, such as "calming child down," "giving attention," "rewarding/punishing/scolding child," "1:1-supervision," and "parent sleeping in child bed" [3]. While participants perceived many of these measures to be effective, these interventions all require time and physical presence. Yet Hoffmann et al. report that participants were better able to cope with their child's disorder when they had time alone and outside the family [3]. These results seem conflicting: How do caregivers get time for themselves when they must constantly provide care and manage the behavior problems of MPS? Hoffmann et al. do not provide information about how participants feel actively implementing these coping strategies and their overall perceptions of caregiver burden. Therefore, qualitative studies are needed to examine whether these coping strategies are actually feasible in practice. Anthropological methods, such as participant observation, may be used to report how caregivers implement these strategies on a daily basis and identify whether these strategies should be recommended for all families.

Interestingly, Hoffmann et al. also report that antipsychotics were prescribed and rated highly effective against challenging behaviors [3]. However, previous studies have reported that antipsychotics should not be recommended for people with MPS because of their limited efficacy and potential for adverse side effects [4]. These conflicting results make it very difficult for clinicians and families to manage the behavior problems of MPS. Further qualitative research may help evaluate how antipsychotics affect the lived experiences of people with MPS, which may provide further insights on the efficacy of antipsychotics for this population. 
While many factors can influence the impact of behavior problems, we must not forget that challenging behaviors can cause tremendous social isolation for families. My parents and I rarely see extended family, visit with friends, or go out in public because of fear that my brother will hurt someone. Moreover, support groups rarely discuss aggression and other behavior problems, making it seem like we are the only family with these difficult experiences. The research conducted by Hoffmann et al. is extremely important because it helps families like mine recognize that we are not alone and there are strategies to help cope with challenging behaviors. However, the recommendations outlined in this article can help studies dig even deeper to understand the broader impact of challenging behaviors and identify the most effective interventions for support.

\section{Response to: Evaluating strategies to manage and endure challenging behaviors in mucopolysaccharidoses}

Frederik Hoffmann ${ }^{2 *}$ Markus Ries $^{3}$

*Correspondence: frederik.hoffmann@klinikum-fuerth.de

${ }^{2}$ Center for Pediatric and Adolescent Medicine, Klinikum Fürth, Jakob-Henle-Straße I, 90766 Fürth, Germany

${ }^{3}$ Pediatric Neurology and Metabolic Medicine, Center for Rare Diseases, Center for Pediatric and Adolescent Medicine, Heidelberg University Hospital, Im Neuenheimer Feld 430, 69120 Heidelberg, Germany

\section{Dear Professor Palau,}

Thank you for letting us have Grant's response to our research. We have studied Grant's letter with great interest and certainly appreciate his important comments. We feel honoured by such scholarly feedback and are happy to comment on it.

Grant strongly underlines the urgent need for a better understanding of the behavioral problems associated with neuronopathic Mucopolysaccharidoses (MPS) and their deep-reaching effects on affected families, as well as the problems in surveying them. He concretely illustrates how aggressive behavior further impedes the intense and stressful demands on the people caring for persons with neuronopathic MPS. His experiences conform with the findings of our study, which pinpoint out aggressive behavior as one of the most wearing and least manageable problems associated with this disorder. Furthermore, the social isolation that results from the challenging behavior is a core problem with MPS, as it reduces external support resources. Accordingly, parents have reported an open exposure to the disorder and its difficulties as advice to 'recently diagnosed' families [3]. We agree with Grant, that the awareness of affected families' situation and the removal of taboos seems a cuttingedge element in the commerce with the disease.
Against the background of patients being intellectually disabled and nonverbal, as emphasized in our publication, behavior such as aggression must be considered as communication of indisposition [3, 11]. We have mentioned that it is important to address potential physical factors first, in order to allow for behavioral strategies to work out $[3,4]$. In this context, availability by a practitioner, who is familiar with the child and its condition, seems crucial. Parents did not report the use of pain killers in our study [3]. However, in our clinical experience we have seen the positive effects of antispastic, hence analgetic treatment via baclofen pump on sleep difficulties.

We conform with Grant that the individual medical history and medical treatment is fundamental for understanding child behavior and possible solutions. Yet, a wide collection of data will decrease study participants' response rates (a factor that must not be underestimated in research intense conditions like MPS). Therefore, the study design needed to balance these factors in order to answer our research questions. Our primary interest focused on the behavioral phenotype and the collection of parental experiences. With this aim in mind, all medication prompted by parents was presented in the publication, each with its estimated effectiveness on difficult behavior. The high reporting rate of antipsychotic medication shows, that its prescription is common in the treatment of sleep disturbance and hyperactivity in MPS [3]. We have underlined that antipsychotic medication may have strong adverse effects, especially in children with MPS, and must therefore be prescribed with particular precaution [3, 4, 12-14]. However, given its high estimated effectiveness on challenging behavior, the use of antipsychotic medication should not be dismissed entirely without careful specialist evaluation. An individual (re-)consideration of risks and benefit before and after the beginning of such treatment is considered inevitable and severe adverse effects may call for a discontinuation of treatment. Medication should be evaluated in collaboration with a pediatric psychiatrist. However, regional availability of such medical support is often limited and represents a resource constraint.

Although Enzyme Replacement Therapy (ERT) or Hematopoietic Stem Cell Transplantation (HSCT) can have an influence on the disease trajectory, its use is limited to a minority of affected children [15-18]. In our study's population only one child had received such specific therapy [3]. Due to the rarity of the disorder, the child's mother feared to endanger her anonymity. We respected her wish for confidentiality and did not state the specific therapies her child had received prior to the 
study. Nevertheless the individual treatment history is essential for the understanding of child behavior in MPS.

Symptomatic behavior in MPS shows distinct changes over time. Hyperactivity, as one of the core symptoms in children, would diminish in the process of ongoing neuronal impairment and ultimately lead to a vegetative state in most patients [19-21]. Our study focused on the pediatric behavioral phenotype and referring challenges, which lead to the exclusion of adult individuals in our study protocol. We are thankful for Grants accentuation, that care demands do not end with the age of 18 years but shift towards other challenges. This being so, caregiving will tend to be hindered by adult patients' physical strength, whilst overall patient activity declines. Again, siblings may be called on to take responsibility. This underlines the importance of external support for affected families in a post-pediatric population. We agree with Grant, that studies investigating challenges of care demands in adult patients with MPS are urgently needed.

Our questionnaire addressed caregivers of children with MPS. The fact that it was answered mostly by mothers may be representative for mothers being primary caregivers in MPS [8]. Grant noted that sibling stress can't be directly measured in our study. In fact, in only one of 34 cases, a sibling answered our questionnaire herself. As illustrated in previous studies, siblings of children with chronic conditions rather internalize their stress, trying not to further burden their families with their own problems [11, 22, 23]. Therefore studies directly addressing siblings are needed. Furthermore programs to support, connect and empower siblings of chronically ill children are highly important [24].

Patient care demands high mental and physical efforts $[8,11,25]$. Nevertheless, affected families must not neglect their own wellbeing and recovery, in order to prevent burnout and master ongoing care demands. Grant highlights this dilemma by raising concerns about the practicability of time-consuming measures. The timely and psychological efforts accompanying any coping measure is highly individual and depends on multiple factors of the patient (degree of disability, extent of challenging behavior such as aggression) and caregiver (physical and mental robustness, resources) [11]. In our study, we have tried to gather parental experiences and state possible toeholds in the contact with affected children. The evaluation of cost and benefit of specific measures must be individual and curtailed to distinct needs and resources in order to find a balance that allows for long-standing care. The conflict of care demands and recovery underlines the importance of external support for affected families.
The findings of our study may serve as a first step towards using parental experience with problems of poor manageability. Future studies, ideally in a controlled study design, are urgently needed to monitor efficacy, safety, practicability and use of specific measures.

\section{Abbreviations}

MPS: Mucopolysaccharidosis; ERT: Enzyme replacement therapy; HSCT: Hematopoietic stem cell transplantation.

\section{Acknowledgements}

Not applicable.

\section{Authors' contributions}

NG drafted the manuscript, critically reviewed the manuscript, and approved the final manuscript as submitted. FH drafted and critically reviewed the manuscript. MR critically reviewed and approved the final manuscript as submitted.

Funding

No funding was secured for this manuscript.

Availability of data and materials

Not applicable.

Ethics approval and consent to participate

Not applicable.

\section{Consent for publication}

Not applicable.

\section{Competing interests}

NG serves in a non-paid capacity as the President and Founder of Siblings with a Mission, a support group for siblings who have brothers and sisters with complex health conditions. NG also serves in a non-paid capacity on the Board of Directors of the Sibling Leadership Network and on the Sibling Resource Committee of the National MPS Society. NG has a twin brother who has MPS.

Received: 26 November 2020 Accepted: 1 March 2021

Published online: 08 April 2021

References

1. Shapiro EG, Escolar ML, Delaney KA, Mitchell JJ. Assessments of neurocognitive and behavioral function in the mucopolysaccharidoses. Mol Genet Metab. 2017;122S:8-16. https://doi.org/10.1016/j.ymgme.2017.09. 007.

2. Eisengart JB, King KE, Shapiro EG, Whitley CB, Muenzer J. The nature and impact of neurobehavioral symptoms in neuronopathic Hunter syndrome. Mol Genet Metab Rep. 2020;22:100549. https://doi.org/10.1016/j. ymgmr.2019.100549.

3. Hoffmann F, Hoffmann S, Kunzmann K, Ries M. Challenging behavior in mucopolysaccharidoses types I-III and day-to-day coping strategies: a cross sectional explorative study. Orphanet J Rare Dis. 2020;15:275. https://doi.org/10.1186/s13023-020-01548-9.

4. Escolar ML, Jones SA, Shapiro EG, Horovitz DDG, Lampe C, Amartino H. Practical management of behavioral problems in mucopolysaccharidoses disorders. Mol Genet Metab. 2017;122S:35-40. https://doi.org/10.1016/j. ymgme.2017.09.010.

5. Grant N. Investigating the neurobehavioral symptoms of neuronopathic Hunter syndrome. Mol Genet Metab Rep. 2020;22:100566. https://doi. org/10.1016/j.ymgmr.2020.100566. 
6. Moog U, van Mierlo I, van Schrojenstein Lantman-de Valk HMJ, Spaapen L, Maaskant MA, Curfs LMG. Is Sanfilippo type B in your mind when you see adults with mental retardation and behavioral problems? Am J Med Genet Part C Semin Med Genet. 2007;145C(3):293-301. https://doi.org/ 10.1002/ajmg.c.30142.

7. Grant N. Sibling and family caregivers. BMJ. 2018;362:k3158. https://doi. org/10.1136/bmj.k3158.

8. Somanadhan S, Larkin PJ. Parents' experiences of living with, and caring for children, adolescents and young adults with Mucopolysaccharidosis (MPS). Orphanet J Rare Dis. 2016;11:138. https://doi.org/10.1186/ s13023-016-0521-0.

9. Lutz ASF. We walk: life with severe autism. Ithaca [New York]: Cornell University Press; 2020. (The Culture and Politics of Health Care Work).

10. Arnold CK, Heller T, Kramer J. Support needs of siblings of people with developmental disabilities. Intellect Dev Disabil. 2012;50(5):373-82. https://doi.org/10.1352/1934-9556-50.5.373.

11. Malcolm C, Adams S, Anderson G, Gibson F, Hain R, Morley A, et al. The symptom profile and experience of children with rare life-limiting conditions: Perspectives of their families and key health professionals. In: Faculty of Health Sciences and Sport Research Reports. University of Stirling. Cancer Care Research Centre. 2011. http://hdl.handle.net/1893/ 12772. Accessed 1 Jan 2021.

12. Cleary MA, Wraith JE. Management of mucopolysaccharidosis type III. Arch Dis Child. 1993. https://doi.org/10.1136/adc.69.3.403.

13. Kalkan Ucar S, Ozbaran B, Demiral N, Yuncu Z, Erermis S, Coker M. Clinical overview of children with mucopolysaccharidosis type III A and effect of Risperidone treatment on children and their mothers psychological status. Brain Dev. 2010. https://doi.org/10.1016/j.braindev.2008.12.010.12.

14. Roberts J, Stewart C, Kearney S. Management of the behavioural manifestations of Hunter syndrome. Br J Nurs. 2016. https://doi.org/10.12968/ bjon.2016.25.1.22

15. Clarke LA, Wraith JE, Beck M, Kolodny EH, Pastores GM, Muenzer J, et al. Long-term efficacy and safety of laronidase in the treatment of mucopolysaccharidosis I. Pediatrics. 2009. https://doi.org/10.1542/peds. 2007-3847.

16. Muenzer J, Beck M, Eng CM, Giugliani R, Harmatz P, Martin R, et al. Longterm, open-labeled extension study of idursulfase inthe treatment of
Hunter syndrome. Genet Med. 2011. https://doi.org/10.1097/GIM.0b013 e3181fea459.

17. Scarpa M, Orchard PJ, Schulz A, Dickson PI, Haskins ME, Escolar ML, et al Treatment of brain disease in the mucopolysaccharidoses. Mol Genet Metab. 2017. https://doi.org/10.1016/j.ymgme.2017.10.007.

18. Barone R, Pellico A, Pittala A, Gasperini S. Neurobehavioral phenotypes of neuronopathic mucopolysaccharidoses. Ital J Pediatr. 2018. https://doi. org/10.1186/s13052-018-0561-2.

19. Neufeld EF, Muenzer J. The Mucopolysaccharidoses. Online Metab Mol Bases Inher Dis. 2001. https://doi.org/10.1036/ommbid.165.

20. Valstar MJ, Ruijter GJ, van Diggelen OP, Poorthuis BJ, Wijburg FA. Sanfilippo syndrome: a mini-review. J Inherit Metab Dis. 2008. https://doi.org/ 10.1007/s10545-008-0838-5.

21. Holt JB, Poe MD, Escolar ML. Natural progression of neurological disease in mucopolysaccharidosis type II. Pediatrics. 2011. https://doi.org/10. 1542/peds.2010-1274.

22. Fleary SA, Heffer RW. Impact of growing up with a chronically ill sibling on well siblings' late adolescent functioning. Int Scholar Res Netw Fam Med. 2013. https://doi.org/10.5402/2013/737356.

23. Sharpe D, Rossiter L. Siblings of children with a chronic illness: a metaanalysis. J Pediatr Psychol. 2002. https://doi.org/10.1093/jpepsy/27.8.699.

24. Siblings with a mission. http://www.siblingswithamission.org/our-missi on.html. Accessed 2 Jan 2021.

25. Grant S, Cross E, Wraith JE, Jones S, Mahon L, Lomax M, et al. Parental social support, coping strategies, resilience factors, stress, anxiety and depression levels in parents of children with MPS III (Sanfilippo syndrome) or children with intellectual disabilities (ID). J Inherit Metab Dis. 2013. https://doi.org/10.1007/s10545-012-9558-y.

\section{Publisher's Note}

Springer Nature remains neutral with regard to jurisdictional claims in published maps and institutional affiliations.
Ready to submit your research? Choose BMC and benefit from:

- fast, convenient online submission

- thorough peer review by experienced researchers in your field

- rapid publication on acceptance

- support for research data, including large and complex data types

- gold Open Access which fosters wider collaboration and increased citations

- maximum visibility for your research: over 100M website views per year

At BMC, research is always in progress.

Learn more biomedcentral.com/submissions 